\title{
The Isomerism of Cobalt(III) Histidinato Chelates
}

\author{
SVEN BAG GER, KEITH GIBSON and CARSTEN S. SøRENSEN \\ Chemistry Department A, Building 207, The Technical University of Denmark,
DK-2800 Lyngby, Denmark
}

\begin{abstract}
Circular dichroism and proton magnetic resonance spectra of three isomers of cobalt(III)-L-histidinato complexes have been measured. A new cobalt(III)-DL-histidinato complex has been isolated and characterized.
\end{abstract}

This study of histidine chelation in monomeric cobalt(III) complexes is part 1 of an investigation of the bonding details in dinuclear, dioxygen-bridged cobalt(III) complexes with histidine as ligand. ${ }^{1}$

Fig. 1. Histidinate with the numbering of atoms used. L-Histidine has the $(S)$-configuration in the Cahn-Ingold-Prelog notation.<smiles>N[C@@H](Cc1c[nH]cn1)C(=O)[O-]</smiles>

Histidinate (Fig. 1) has three potential metal binding sites: the amino nitrogen atom, the nitrogen atom number 3 of the imidazole ring, and a carboxylate oxygen atom. In the case of tridentate ligation in an octahedral complex only facial attachment is possible, meridional chelation being excluded for steric reasons.

Accordingly nine different isomers of the bis(histidinato)cobalt(III) complex with tridentate histidinate may exist as indicated in Fig. 2.

Zompa et $a .^{2,3}$ have separated a violet, a red, and an orange isomer of bis(L-histidinato)cobalt(III) and by means of their electronic absorption spectra correlated them to the structures trans-carboxylate $\left(3 \mathrm{~L}_{1}\right)$, transimidazole $\left(1 L_{L}\right)$, and trans-amino $\left(2 L_{L}\right)$, respectively. This assignment was later corroborated by Schmidtke, ${ }^{4}$ who treated Zompas spectra on the basis of the "angular overlap model".

In this work we have confirmed the separation and the electronic spectra of these three $\mathrm{Co}(\mathrm{L}-\mathrm{his})_{2}{ }^{+}$isomers* and have measured their $\mathrm{CD}$ and $\mathrm{PMR}$ spectra.

$*$ his ${ }^{-} \equiv$ histidinate

Acta Chem. Scand. 26 (1972) No. 6 


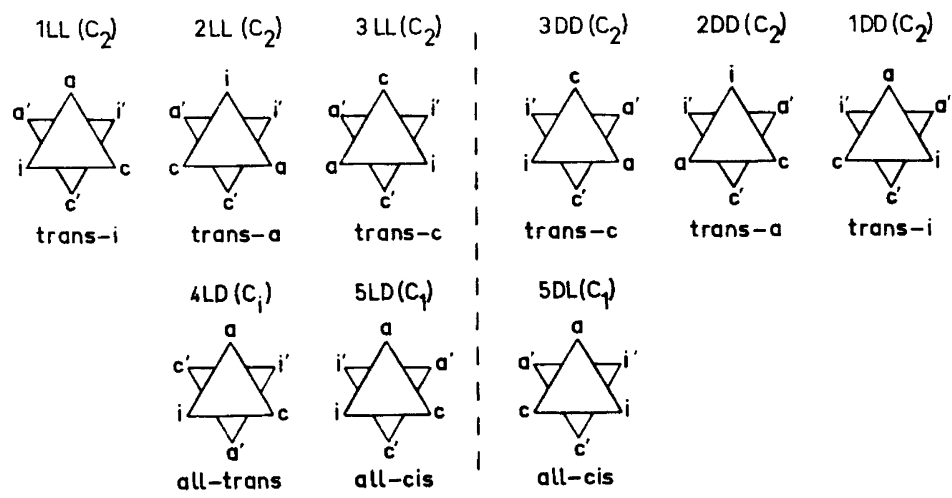

Fig. 2. Isomers of octahedral complexes with two histidinate ligands. I and D denote $\mathrm{L}_{\text {- }}$ and D-histidinate. a, c, and i indicate the amino, the carboxylate, and the imidazole groups. Dashes are used to distinguish the two ligands. Isomers with the same number are mirror images. The symmetry groups are given in parentheses by the Schoenflics symbols.

We have also studied the complexes formed with racemic histidinate, and have isolated and characterized rac-all-cis-[Co(D-his)(L-his) $] \mathrm{Br}(5 \mathrm{DL}+5 \mathrm{LD})$.

\section{EXPERIMENTAL}

Materials. $\mathbf{I}_{-}$- and DL-Histidine (purissimum, chromatographic purity) were obtained from Fluka. All other chemicals were analytical grade. The cation exchange resin used was 50-100 mesh Dowex 50W-X4 (large effective pore size).

Apparatus. Electronic absorption spectra were measured with a Cary 11 recording spectrophotometer and CD spectra with a Roussel-Jouan Dichrographe II, all measurements at room temperature. Normally PMR spectra were recorded at $60 \mathrm{MHz}$ with a Varian A-60 spectrometer at about $30^{\circ} \mathrm{C}$. A $100 \mathrm{MHz}$ Varian HA-100 spectrometer was used for the double-resonance experiments.

Preparations for chromatography. $\mathrm{CoCl}_{2} \cdot 6 \mathrm{H}_{2} \mathrm{O}(3.57 \mathrm{~g}, 15 \mathrm{mmol})$ and either $\mathrm{L}_{-}$or DL-histidine $(5.13 \mathrm{~g}, 33 \mathrm{mmol})$ were dissolved in $100 \mathrm{ml}$ water, and $0.5 \mathrm{~g}$ activated charcoal was added. Air was bubbled through the solution, while the temperature was maintained at about $75^{\circ} \mathrm{C}$. When the colour had changed from brown to red (ca. $\left.90 \mathrm{~min}\right)$ the solution was cooled and the charcoal was filtered off.

Separation of isomers. A column of internal diameter $4.1 \mathrm{~cm}$ was packed with cation exchanger in the $\mathrm{K}^{+}$form to give a resin bed $15 \mathrm{~cm}$ deep. About $50 \mathrm{ml}$ of the solution. of isomers, prepared as above, was run on to the column, and eluted with a $0.05 \mathrm{M}$ aqueous $\mathrm{KBr}$ solution at a rate of $c a .4 \mathrm{ml} / \mathrm{min}$.

When separation had occurred (ca. 2 days), the column was allowed to run dry, and the resin containing the individual bands removed, transferred to smaller columns and washed out with $1 \mathrm{M} \mathrm{KBr}$. (4 M KBr was used for the orange component of $\mathrm{Co}\left(\mathrm{L}_{\mathrm{L}}-\mathrm{his}_{\mathrm{s}}\right)_{\mathrm{a}}^{+}$.)

Brown oxidation products that stayed at the top of the column were always discarded.

If required, the resulting $\mathrm{KBr}$ containing solutions were concentrated with a rotatory evaporator under reduced pressure; any $\mathrm{KBr}$ precipitated during the process was removed by filtration.

The $\mathrm{R}$-values quoted for the isomers are the distance (in $\mathrm{cm}$ ), travelled by the centre of the band, divided by the volume of eluent (in 1) and by the column cross section (in $\left.\mathrm{cm}^{2}\right)$.

Preparation of rac-all-cis-[Co(D-his)(L-his)]Br. A solution of Co(III)-DL-histidinate, prepared as for chromatography, was evaporated to half its volume, and an equal volume

Acta Chem. Scand. 26 (1972) No. 6 
of a $\mathrm{KBr}$ solution $(60 \mathrm{~g} / 100 \mathrm{ml})$ was added. On standing for some days dark red crystals formed; these were filtered off, washed with cold water and ethanol and dried in the air. Once crystals are at hand, these may advantageously be used for seeding in subsequent preparations. Yield $1.4 \mathrm{~g}(21 \%$ of total Co). (Found: C $32.21 ; \mathrm{H} \mathrm{3.61;} \mathrm{N} \mathrm{18.86;} \mathrm{Br} \mathrm{17.86.}$

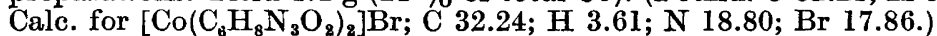

PMR Experiments. Solutions of the three fractions of $\mathrm{Co}\left(\mathrm{L}_{4}-\mathrm{his}\right)_{2}{ }^{+}$were concentrated to ca. $0.2 \mathrm{M}$ with removal of precipitated $\mathrm{KBr} .0 .5 \mathrm{ml}$ of these solutions were evaporated to dryness and redissolved in $0.5 \mathrm{ml} \mathrm{D}_{2} \mathrm{O}$. This process was repeated, and the final solution transferred to an NMR tube.

rac-all-cis-[Co(D-his)(L-his)] $\mathrm{Br}$ was dissolved in $0.5 \mathrm{ml} \mathrm{D}_{2} \mathrm{O}(35 \mathrm{mg}, 0.16 \mathrm{M})$ evaporated and redissolved in $0.5 \mathrm{ml} \mathrm{D}_{2} \mathrm{O}$.

$\mathrm{A}$ pH meter with glass and calomel electrodes was used to get $\mathrm{pD}$ values according to the relationship $\mathrm{pD}=\mathrm{pH}_{\text {reading }}+0.4 .^{5}$

A trace of tert-butylalcohol was added to the tubes, the methyl resonance $(\delta=-1.23$ relative to TMS) being taken as an internal reference; for the double-resonance experiment an external TMS reference was used.

All resonances were observed downfield from TMS giving negative $\delta$-values; the negative sign has been omitted throughout in the following.

Analyses. The elemental analysis was carried out by the Microanalytical Department, Chemistry Laboratory II, University of Copenhagen.

Extinction coefficients of the Co(L-his) ${ }_{2}^{+}$isomers are based on cobalt analyses. Solutions, containing at least $0.2 \times 10^{-3} \mathrm{~mol}$ cobalt, were fumed with conc. $\mathrm{H}_{2} \mathrm{SO}_{4}$ $\mathrm{Co}(\mathrm{II})$ in the resulting clear solutions was determined by addition of EDTA and backtitration with $\mathrm{Zn}$ following the method of Kiss. ${ }^{6}$ The results are estimated to be accurate to within $\pm 3 \%$.

\section{RESULTS}

Chromatography. The cation-exchange column chromatography of the $\mathrm{Co}$ (III)-L-histidinate solution leads to the separation of a violet, a red, and an orange band with $\mathrm{R}$-values $0.08,0.03$, and 0.02 , respectively. The mol ratio violet:red:orange was found by absorption measurements to be $3: 13: 1$.

Our attempts to isolate crystals of the three isomers have hitherto been unsuccessful.

The chromatography experiments with $\mathrm{Co}(\mathrm{III})$-DL-histidinate yielded one red band only, having $R=0.05$. No violet or orange bands were observed. Concentration of the red band eluted with $\mathrm{KBr}$ solution resulted in precipitation of dark red crystals with an absorption spectrum identical to that of rac-all$c i s-\left[\mathrm{Co}(\mathrm{D}-\mathrm{his})\left(\mathrm{L}_{-}-\mathrm{his}_{\mathrm{S}}\right)\right] \mathrm{Br}$ prepared directly from the reaction mixture.

One chromatographic experiment with $\mathrm{Co}$ (III)-DL-histidinate was performed with $\mathrm{KCl}$ as the eluting agent in order to get a concentrated PMR sample of the red band without the all-cis complex precipitating as the bromide (Spectrum VI, Table 1).

Absorption and circular dichroism. The visible absorption and CD spectra of the $\mathrm{KBr}$ containing solutions of the three $\mathrm{Co}(\mathrm{L}-\mathrm{his})_{2}{ }^{+}$isomers are given in Fig. 3.

On varying the $\mathrm{KBr}$ concentration between $0.16 \mathrm{M}$ and $4 \mathrm{M}$, the shape of the red isomer absorption spectrum did not change, but the extinction coefficients increased about $4 \%$.

The absorption and CD spectra of the three isomers were independent of $\mathrm{pH}$ in the range $2-6$, but as the $\mathrm{pH}$ was raised from 6 to 12 a tail from a band in the UV caused an increase in the visible absorption.

Acta Chem. Scand. 26 (1972) No. 6 
Table 1. Data from PMR.

\begin{tabular}{|c|c|c|c|c|c|c|c|c|c|}
\hline \multirow{2}{*}{\multicolumn{2}{|c|}{ Sample }} & \multicolumn{2}{|c|}{$\mathbf{H}_{\mathrm{C}_{2}}$ peaks } & \multicolumn{2}{|c|}{$\mathrm{H}_{\mathrm{C}_{5}}$ peaks } & \multicolumn{2}{|c|}{$H_{C \alpha}$ peaks } & \multicolumn{2}{|c|}{$\left(\mathrm{H}_{\mathrm{C} \beta}\right)_{2}$ peaks } \\
\hline & & $\begin{array}{c}o \\
(\mathrm{ppm})\end{array}$ & Pattern $^{a}$ & $\begin{array}{c}o \\
(\mathrm{ppm})\end{array}$ & Pattern ${ }^{a}$ & $(\mathrm{ppm})$ & Pattern ${ }^{a}$ & $\begin{array}{c}o \\
(\mathrm{ppm})\end{array}$ & Pattern ${ }^{a}$ \\
\hline I & $\begin{array}{l}\text { L-Histidine } \\
\text { (pD 1.4) }\end{array}$ & 8.75 & $2(1.35)$ & 7.50 & 1 & 4.42 & $3(6.5)$ & 3.48 & $2(6.5)$ \\
\hline II & $\begin{array}{l}\text { Red } \\
\mathrm{Co}\left(\mathrm{L}_{-}-\mathrm{his}\right)_{2}+ \\
(\mathrm{pD} 2.5)\end{array}$ & 7.93 & $2(1.4)$ & 7.31 & $2(1.3)$ & 4.00 & $3(3.7)$ & 3.43 & $2(3.6)$ \\
\hline III & $\begin{array}{l}\text { Violet } \\
\text { Co(L-his) })_{2}+ \\
\text { (pD 5.7) }\end{array}$ & 7.82 & $2(1.3)$ & 7.41 & $2(1.1)$ & 4.07 & h.o. & 3.54 & h.o. \\
\hline IV & $\begin{array}{l}\text { Orange } \\
\text { Co(L-his })_{2}+ \\
\text { (pD 5.2) }\end{array}$ & 7.93 & $2(1.5)$ & 7.26 & $2(1.1)$ & 4.29 & h.o. & 3.67 & h.o. \\
\hline V & $\begin{array}{l}\text { rac-all-cis- } \\
\mathrm{Co} \text { (D-his) }\end{array}$ & 7.93 & $2(1.45)$ & 7.38 & $2(1.4)$ & 4.17 & $3(3.9)$ & 3.46 & $2(3.6)$ \\
\hline & $\begin{array}{l}(\mathrm{L}-\mathrm{his})^{+} \\
(\mathrm{pD} 6.5)\end{array}$ & 7.03 & $2(1.5)$ & 7.15 & $2(1.4)$ & 3.83 & $3(3.7)$ & 3.48 & $2(3.6)$ \\
\hline & Co(III)-DL-his & 7.95 & 2 & 7.45 & 2 & 4.26 & 3 & 3.51 & \\
\hline VI & $\begin{array}{l}\text { (mixture) } \\
\text { (pD 2.0) }\end{array}$ & $\begin{array}{l}7.06 \\
7.55\end{array}$ & 2 & $\begin{array}{l}7.20 \\
7.31\end{array}$ & 2 & 3.86 & 3 & & \\
\hline
\end{tabular}

a Number of peaks, and, in parentheses, their separation in $\mathrm{Hz}$. h.o. $\equiv$ higher order spin patterns.

The dark red crystals of rac-all-cis-[Co(D-his)(L-his)]Br dissolved in water showed the absorption spectrum given in Fig. $4\left(\varepsilon_{\max }=87.3\right.$ at $\left.495 \mathrm{~nm}\right)$; its $\mathrm{pH}$ dependence was similar to that of the $L_{1} \mathrm{~L}_{-}$-isomers.

Proton magnetic resonance. The $60 \mathrm{MHz}$ spectra in $\mathrm{D}_{2} \mathrm{O}$ of $\mathrm{L}_{\mathrm{L}}$-histidine (I), the three $\mathrm{Co}(\mathrm{L}-\mathrm{his})_{2}{ }^{+}$isomers (II, III, and IV), rac-all-cis-Co(D-his)(L-his) ${ }^{+}$ (V), and the chromatographically purified $\mathrm{Co}(\mathrm{III})$-DL-histidinate mixture (VI) are outlined in Table 1 . The integration of spectra $\mathrm{I}-\mathrm{V}$ gave $\mathrm{H}_{\mathrm{C} 2}: \mathrm{H}_{\mathrm{C} 5}: \mathrm{H}_{\mathrm{C} \alpha}: \mathrm{H}_{\mathrm{C} \beta}$ equal to 1:1:1:2. Addition of a drop of $\mathrm{DCl}$, giving a $\mathrm{pD}$ of $\sim 0.6$, did not cause significant changes in the spectra reported.

Two independent preparations of rac-all-cis-[Co(D-his)(L-his) $] \mathrm{Br}$ showed the spectrum in Fig 5; this was analyzed by the double-resonance technique. On irradiating at the resonance frequency of doublet $\mathrm{A}, \mathrm{B}$ collapsed to a singlet, while $C$ and $D$ remained as doublets. Irradiation of $B$ caused decoupling of A. By irradiation of $\mathrm{G}, \mathrm{E}$, and $\mathrm{F}$ were decoupled. Irradiation of $\mathrm{E}$ and then $F$ revealed that $G$ consists of two nearly superimposed doublets, the higher field doublet arising from coupling with $\mathrm{E}$, the other from coupling with $\mathrm{F}$.

Spectrum VI shows six resonances in the low field region. Four of these correspond closely to those of the all-cis isomer, spectrum V. The other two 


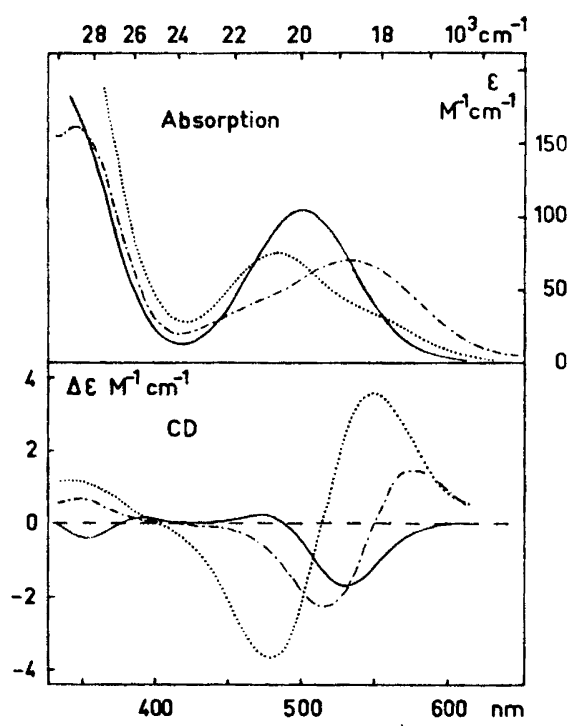

Fig. 3. Solution absorption and CD spectra of the violet $(-\cdot-\cdot-)$, red $(-)$, and orange $(\ldots \ldots)$ components of $\mathrm{Co}\left(\mathrm{I}_{1} \text {-his }\right)_{2}{ }^{+}$ at $\mathrm{pH} c a$. 4. The violet and red solutions were ca. $0.5 \mathrm{M} \mathrm{KBr}$, whereas the orange solution was saturated with $\mathrm{KBr}$.

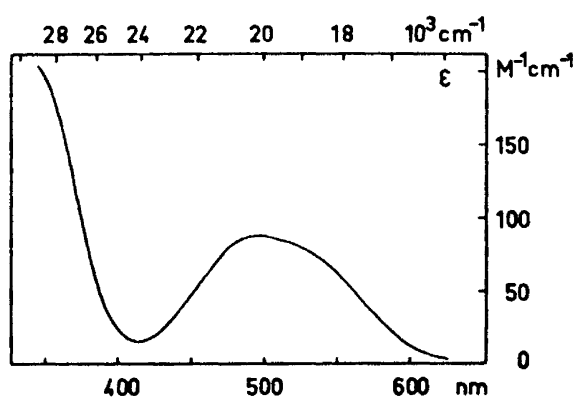

Fig. 4. Solution absorption spectrum of rac-all-cis-[Co(D-his)(L-his) $] \mathrm{Br}$ in $\mathrm{H}_{2} \mathrm{O}$.

( $\delta$ values 7.55 and 7.31 ) were much weaker, their combined intensity being ca. $10 \%$ of the total intensity of all six peaks.

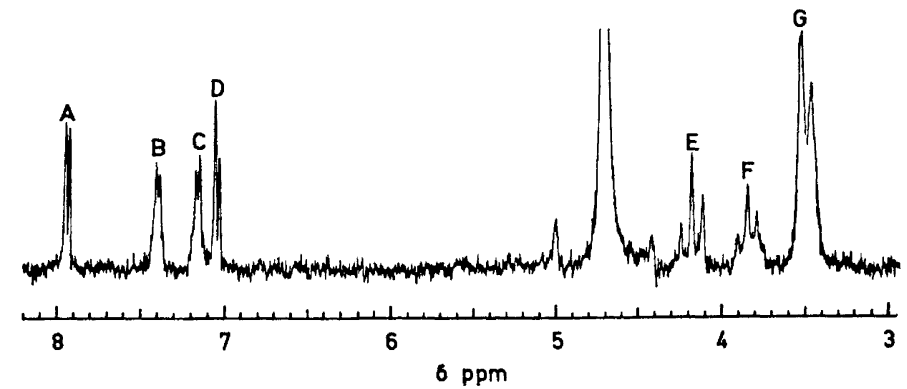

Fig. 5. $60 \mathrm{MHz}$ PMR spectrum of rac-all-cis-[Co(D-his)(L-his)]Br in $\mathrm{D}_{2} \mathrm{O}$. The ratio of peak areas A:B:C:D:E:F:G is equal to $1: 1: 1: 1: 1: 1: 4$.

\section{DISCUSSION}

The splitting pattern in the lowest energy spin-allowed $d-d$ band was used $^{4}$ in the assignment of structures to the three Co(L-his) ${ }_{2}{ }^{+}$isomers. The semi-empirical calculations ${ }^{4}$ predict two components in this band of the Acta Chem. Scand. 26 (1972) No. 6 


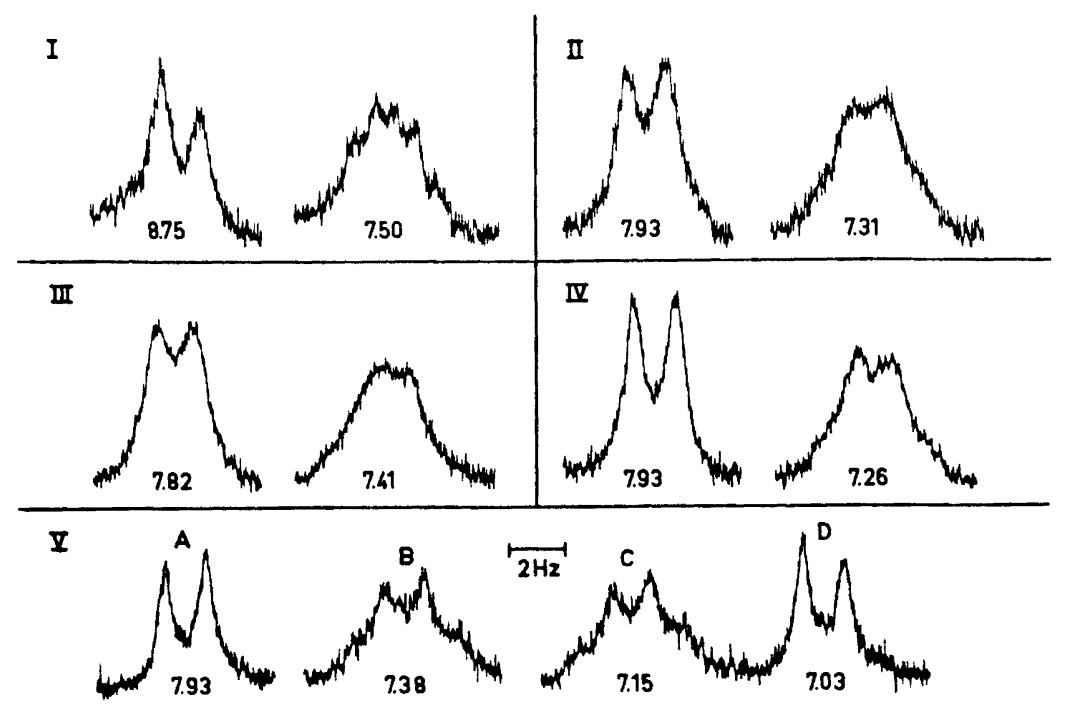

Fig. 6. Expanded scale $60 \mathrm{MHz}$ spectra of $\mathrm{H}_{\mathrm{C}_{2}}$ and $\mathrm{H}_{\mathrm{C}_{5}}$ protons. $\delta$-value and spectrum number are indicated; compare Table 1 and Fig. 5.

trans-carboxylate and of the trans-amino complexes, the calculated patterns being in good agreement with the experimental absorption spectra of the violet and the orange isomers, respectively. As seen in Fig. 3, the CD spectra show a negative and a positive component in the two cases. The trans-imidazole structure was expected ${ }^{4}$ to exhibit only a small splitting. This agrees well with the absorption spectrum of the red isomer, which has no discernible splitting; but the CD spectrum reveals that more than one transition occurs, as a negative and a positive component are observed in the first $d$ - $d$ band.

The PMR spectra of the diamagnetic complexes are composed of one or more sets of peaks, each of which resembles the spectrum of histidine in acid solution.

The assignments of $\mathrm{H}_{\mathrm{C} \alpha}$ and $\mathrm{H}_{\mathrm{C} \beta}$ protons in the spectra of the complexes are straightforward from integration curves and splitting patterns. In histidine itself the resonances of the protons on the imidazole moiety, $\mathrm{H}_{\mathrm{C} 2}$ and $\mathrm{H}_{\mathrm{C} 5}$, have been assigned ${ }^{7}$ as shown in Table 1 on the basis of the $\mathrm{pH}$ dependence of their chemical shifts. On an expanded $\delta$-scale it is seen (Fig. 6) that in all spectra the peaks of $\mathrm{H}_{\mathrm{c} 2}$ and $\mathrm{H}_{\mathrm{C} 5}$ protons differ in shape, one of them not being a simple doublet. In histidine the broad peak is known to be due to $\mathrm{H}_{\mathrm{C} 5}$, and assuming that this is also the case in the complexes we have assigned the $\mathrm{H}_{\mathrm{C} 2}$ and $\mathrm{H}_{\mathrm{C} 5}$ peaks as shown in Table 1 . The broadening of the $\mathrm{H}_{\mathrm{C} 5}$ peak possibly arises from coupling with the $2 \mathrm{H}_{\mathrm{c} \beta}$ protons, in addition to the coupling with $\mathrm{H}_{\mathrm{C} 2}$.

The PMR spectra of the $\mathrm{Co}(\mathrm{L}-\mathrm{his})_{2}{ }^{+}$complexes are consistent with their $C_{2}$ symmetry which implies two equivalent histidinate ligands.

The spectrum of rac-all-cis-[Co(D-his)(L-his) $] \mathrm{Br}$ is composed of two histidinetype spectra. The all-cis complexes, structures 5LD and 5DL in Fig. 2, have 
$C_{1}$ symmetry, and are the only isomers with two non-equivalent ligands. The complex isolated must therefore be a racemic mixture of the two.

The double resonance experiments make clear that peaks A and B (Fig. 5) originate from the same imidazole ring, and that $\mathrm{C}$ and $\mathrm{D}$ must therefore arise from the other ligand. We note that the $\mathrm{H}_{\mathrm{c} 2}$ proton $\mathrm{D}$ in the all-cis spectrum is situated so far upfield that it appears at higher field than its corresponding $\mathrm{H}_{\mathrm{C} 5}$ proton, $\mathrm{C}$; this high shielding may be a clue to its precise location in the structure.

The synthesis from racemic histidine could theoretically yield all nine isomers shown in Fig. 2, and so five bands would potentially be separable on an optically inactive resin. In fact we only observe one red band. The absorption spectrum of the eluted band is indistinguishable from that of rac-all-cis$\mathrm{Co}(\mathrm{D}$-his $)\left(\mathrm{L}_{\mathrm{L}} \text {-his }\right)^{+}$; its PMR spectrum, however, does indicate the presence of species other than the all-cis isomer, as additional weak peaks are observed (VI, Table 1); and assuming that these are due to the all-trans complex (4L,D), they account for $c a .10 \%$ of the isomers present.

It is clear that $\mathrm{DL}$ isomers are predominant in the $\mathrm{Co}(\mathrm{III})$-DL-histidinate preparation. In the labile, octahedral bis(histidinato) complexes of $\mathrm{Co}$ (II) and $\mathrm{Ni}(\mathrm{II})$ a significant stereoselective effect favouring the mixed $\mathrm{DL}_{4}$-metal over the LL- and DD-metal complexes has also been found. ${ }^{7-10}$

It has been suggested ${ }^{8}$ that the imidazole groups in octahedral, bis(histidinato) complexes because of steric hindrance will be forced into trans position. The observation of the all-cis-, trans-carboxylate-, and trans-amino-Co(his) ${ }_{2}{ }^{+}$ isomers shows that this argument does not hold in Co(III) complexes. The cis-imidazole arrangement has also been proved in the structure determination of the $\mathrm{Co}(\mathrm{II})$ complex $\left[\mathrm{Co}(\mathrm{D}\right.$-his $\left.)\left(\mathrm{I}_{4}-\mathrm{his}\right)\right] .2 \mathrm{H}_{2} \mathrm{O} .{ }^{\mathbf{1 1}}$

Briefly sketched the route for our preparation of the monomeric $\mathrm{Co}$ (III) complexes is

$$
\left.2 \mathrm{Co}(\text { his })_{2} \stackrel{\mathrm{O}_{2}}{\longrightarrow} \text { (his) }\right)_{2} \mathrm{CoO}_{2} \mathrm{Co}(\text { his })_{2} \longrightarrow 2 \mathrm{Co}(\text { his })_{2}{ }^{+}
$$

The intermediate $\mu$-peroxo-bis $\left\{\right.$ bis( $L_{-}$-histidinato)cobalt(III) $\}$complex can be obtained in crystalline form..$^{12}$ In the light of the foregoing discussion numerous isomers are conceivable of this and similar bridged $\mathrm{Co}$ (III) complexes with $\mathrm{D}$ - and L-histidine as terminal ligands. Nevertheless it may turn out that stereoselectivity simplifies the picture in reality, as we have found to be the case for the monomeric $\mathrm{Co}(\mathrm{III})$ complexes.

Acknowledgement. We wish to thank Professor Christian Pedersen, Department of Organic Chemistry, Technical University of Denmark, for placing the NMR equipment at our disposal, and Mr. Ole Bang for help with the cobalt analyses.

\section{REFERENCES}

1. Bagger, S. Acta Chem. Scand. 23 (1969) 975.

2. Zompa, L. J., Sokol, C. S. and Brubaker, C. H. Chem. Commun. 1967701.

3. Zompa, L. J. Chem. Commun. 1969783.

4. Schmidtke, H.-H. Chem. Phys. Letters 4 (1969) 451.

5. Lumry, R., Smith, E. L. and Glantz, R. R. J. Am. Chem. Soc. 73 (1951) 4330.

Acta Chem. Scand. 26 (1972) No. 6 
6. Kiss, T. A. Z. anal. Chem. 208 (1965) 334.

7. MeDonald, C. C. and Phillips, W. D. J. Am. Chem. Soc. 85 (1963) 3736.

8. Ritsma, J. H., Van de Grampel, J. C. and Jellinek, F. Rec. Trav. Chim. 88 (1969) 411.

9. Morris, P. J. and Martin, R. B. J. Inorg. Nucl. Chem. 32 (1970) 2891.

10. Barnes, D. S. and Pettit, L. D. J. Inorg. Nucl. Chem. 33 (1971) 2177.

11. Candlin, R. and Harding, M. M. J. Chem. Soc. A 1970384.

12. Sano, Y. and Tanabe, H. J. Inorg. Nucl. Chem. 25 (1963) 11.

Received November 15, 1971. 